\title{
TRAINING CRITICAL THINKING TO ENHANCE BATTLEFIELD INITIATIVE
}

\author{
Marvin S. Cohen \& Leonard Adelman \\ Cognitive Technologies, Inc. \\ 4200 Lorcom Lane \\ Arlington VA 22207 \\ 703-524-4331 \\ mcohen@cog-tech.com
}

\begin{abstract}
The knowledge and thinking strategies associated with taking initiative were investigated. Training based on the results proved successful in improving tactical battlefield decision making performance.
\end{abstract}

\section{INTRODUCTION}

In a rapidly changing and uncertain task environment, there is sometimes a tradeoff between acting quickly based on familiar responses to past situations and taking time to find a unique solution to the current problem (Cohen, Freeman, \& Wolf, 1996). At the organizational level, a similar tradeoff occurs between risky exploration of new markets, technologies, or tactics versus falling back on existing strengths (March, 1996). Sometimes, individual and organizational dilemmas intersect: When time is constrained and communication is difficult, individuals acting within an organization may have to choose between coordination with other team elements and taking initiative to seize fleeting opportunities (Cohen \& Thompson, 2001). This is a not uncommon predicament in combat: Company A's job is to guard Company B's flank while Company $\mathrm{B}$ secures a bridge that the division intends to cross. Now, however, Company B appears to be stalled in a major firefight some distance from the bridge. Company A cannot raise either Company B or higher headquarters on the radio (and it will take too long for runners to find them and return). Should Company A sit tight until Company B is ready to seize the bridge or until communications are reestablished? Should it go help Company B in the firefight, at the risk of getting bogged down itself? Or should Company A attempt to seize the bridge now - a risky choice, but possibly the only way to accomplish the higher-level purpose of supporting the division in a timely manner?

How can individuals and teams be trained to make decisions that balance the benefits of initiative against its risks? Our approach does not start with an priori normative model of decision making, but with empirically based prescription. We first ask, what strategies and knowledge do experienced decision makers draw on to make decisions about the appropriate degree of initiative in unexpected situations, and how (if at all) do less experienced decision makers differ? This question must be answered by a combination of experimental studies, analysis, and cognitive modeling. We then develop training that attempts to convey the relevant strategies and knowledge to less experienced decision makers. Finally, we test the training to find out whether performance of less experienced decision makers is improved. In this article, we will briefly describe a case study of this method. We analyzed critical incident interviews with experienced Army officers, modeled the results, developed computer-based training, and tested it with students at the Army Command and General Staff College (Cohen, Thompson, Adelman, Bresnick, Shastri, \& Riedel, 2000).

\section{ANALYSIS OF COGNITIVE SKILLS}

Initiative means taking "the first step, or the lead; the act of setting a process or chain of events 
in motion" (Brown, 1993). Interventions are often (though not always) targeted at the decision-actionoutcome cycle of other agents. In business, for example, one may try to influence, predict, or react to the actions of competitors, customers, superiors, subordinates, or co-workers. In combat, one may try to influence, predict, or react to actions of the enemy, other friendly forces, superiors, or subordinates. In all these cases, the earlier and more influential the intervention, the more initiative the person has shown with respect to the targeted process. The essential questions for training are: What are the mental models and the thinking processes that underlie initiative?

We analyzed 25 critical incident interviews and problem-solving sessions with active duty Army officers serving on operations, planning, and intelligence staffs from the battalion to the corps level. We identified clusters of topics that tended to be correlated with one another within and across incidents. We will refer to these correlated groups of concepts, together with their implicit or explicit causal relationships, as mental models. Among these were mental models representing three degrees of initiative, or time orientations, defined in terms of where and how they intervened in the chain of events representing another agent's decisions, actions, and outcomes. The proactive time orientation was present if a friendly action was designed to influence future enemy or friendly intent. The predictive time orientation was present if a friendly action was adopted because a future enemy or friendly action was expected to occur (without the friendly unit's doing anything special to bring it about). The reactive time orientation occurred when a friendly action was adopted because of an enemy or friendly action already accomplished or underway. The three time orientations are not mutually exclusive. A decision maker might be reactive at one level but proactive and/or predictive at other levels, with respect to other decision cycles that belong to the same or different agents. Finally, we modeled the relations among time orientations, other mental models, and degree of experience in a multidimensional space.

Years of experience was significantly correlated with use of a proactive time orientation as well as with reference to higher-level purposes of the organization (i.e., above the level of one's own unit). Moreover, hierarchical analysis of correlations (Johnson, 1967) revealed three basic clusters of mental models, corresponding to the three time orientations: reactive, predictive, and proactive. Proactive decision makers, who tried to impose their will on others, were most likely to think deeply about their own higher-level purpose. Mental models of the other agent's intent and of one's own intent (at the level of one's own unit) were utilized approximately equally often by decision makers who were trying to predict intent as by decisions makers who were trying to influence it. Predictive decision makers were more likely to use a rate of movement mental model, while mental models of reliability of evidence were used both in the predictive orientation (to evaluate predictions) and in the reactive orientation (to figure out why a prediction failed). Alternative causes and effects were considered most often in reactive modes, when decision makers tried to explain a failed expectation. Mental models of action sequence, which specify how one's own actions are to be carried out, were approximately equally important in all three time orientations.

In sum, concepts in this domain appear to be organized into a set of mental models, including purpose, intent, action sequence, alternative causes and effects, and reliability of evidence. These models in turn are organized around a set of more fundamental principles pertaining to initiative, or the time and manner in which uncertainty about other agents is reduced. Focus on high-level purpose and proactive time orientation are strongly correlated with one another and with experience.

\section{A TRAINING STRATEGY}

The training to be described is part of a larger package focused more generally on critical thinking skills in tactical decision making (Cohen, Thompson, Adelman, Bresnick, Shastri, \& Riedel, 2000; Cohen, Freeman, \& Wolf, 1996). The part of interest to us here teaches students the elements of initiative, focusing on how to think critically about purpose and time under conditions of uncertainty. Each segment of the training contains an introduction to the relevant concepts, military examples, historical 
case studies, and interactive exercises with feedback. All exercises involve brief, realistic military scenarios adapted with permission from the tactical decision games published monthly in the Marine Corps Gazette.

The section on time orientation describes questions that need to be asked to fill gaps in proactive, predictive, and reactive mental models. To create a proactive mental plan, for example, the decision maker asks: "What are my purposes? What do I want the enemy to do that will promote those purposes? And what can I do to get him to do it?" To create a predictive plan, the decision maker asks: "What will the enemy do and what strengths or weaknesses are associated with those actions? What are the implications of those strengths and weaknesses for my purposes? And what can I do to avoid the strengths or exploit the weaknesses?" A section of the training on purpose emphasizes the importance of considering not only the purposes of the officer's own unit, but how it is intended to support and provide backup for higher-level purposes of superior units, as well as the tasks of adjacent units.

A section on critical thinking about initiative introduces students to an iterative process in which possible problems are identified and corrected. The primary emphasis is on how each time orientation can be used to address weaknesses in the other time orientations as plans are gradually elaborated and improved. For example, suppose planning begins with a predictive model based on the expectation that an enemy unit will cross a river and be vulnerable to attack as it crosses. A devil's advocate strategy is then used to critique the plan. (An infallible crystal ball says, "The plan will fail. Explain how.") This process brings to light hidden assumptions about enemy intent upon which the plan depends. To make the plan more robust, proactive tactics are developed to lure the enemy across the river. Other proactive tactics are developed to increase the enemy's vulnerability while crossing by using artillery to prevent it from concentrating forces on either side. To guard against the possibility that predictive and proactive tactics fail to achieve their purpose, the plan is further elaborated to include a flexible, reactive orientation in case the enemy does something unexpected. The result is a mutually supportive network in which proactive tactics are utilized to increase the chance that predictive assumptions will turn out to be true, while reactive tactics monitor for the unexpected. Then, the enemy does in fact behave in a surprising manner (heading in a different direction than expected). The initial time orientation now is reactive, to mitigate any immediate threat from the enemy action. The next phase is predictive, to figure out how to exploit any enemy weaknesses that the action exposes or creates (e.g., failing to cross the river leaves a command post relatively undefended on the other side). At the same time, these opportunities may be used to create new weaknesses, i.e., to proactively degrade the enemy's capability to pursue future operations (e.g., by destroying a command post or attacking logistics). The result is a template for reaction to surprise that shifts as rapidly as possible from reactive to predictive to proactive orientations.

\section{FIELD TEST OF THE TRAINING STRATEGY}

\section{Method}

Seventy-eight students at the Army Command and General Staff College, Fort Leavenworth, Kansas, participated in an informal study. All students had the rank of Major, and were enrolled in the spring quarter of an advanced tactics course, taught by LTC William Hadfield. The participants' average length of Army service was 12.7 years, which included an average of 10 major exercises and an average of approximately two years of command staff experience. Over half of the participants $(66 \%)$ had experience in a combat or peacekeeping mission.

Training consisted of a CD-ROM handed out to students, who were asked to review it at home. Participants were asked to respond to a different tactical scenario before and after the training. For this purpose, two brief tactical scenarios (Sanna's Post and Platoon Ambush) were adapted with permission from among the tactical decision games presented in the Marine Corps Gazette. A participant's task was to read the scenario, to develop operations orders, explain the orders, describe alternative plans, list the strengths and weaknesses of all plans, give reasons for choosing the preferred plan, and indicate how weaknesses in the preferred plan are addressed. 
Dependent measures included references to high level purpose, references to proactive, predictive, reactive or predictive-reactive (contingency) plans, and the actual tactics adopted. Unfortunately, results for one of the scenarios (Platoon Ambush) showed very little variability among students (and no significant effects), possibly due to ceiling effects.

\section{Results}

Reaction. In the Sanna's Post scenario, the company mission is to guard the battalion's left flank, and it is necessary to deal with the unexpected presence of enemy vehicles at a small settlement, Sanna's Post, that sits on a tactically important road. The first question, therefore, concerned the reactive time orientation: Did officers adopt any action at all with respect to the unexpected enemy at Sanna's Post (down to and including a simple decision to keep an eye on them)? There was a significant increase in attention to Sanna's Post after training $(F(1,50)=18.041 ; p=$ $0.000)$. Before training only $10.5 \%$ of the officers took any action, no matter how minor, with regard to Sanna's Post, while $63.6 \%$ of the officers took some action after the training.

Purpose. A good argument could be made that the company should take the initiative via an offensive action against the enemy at Sanna's Post, to protect the battalion's left flank. On the other hand, the impact of such an initiative on coordination with the battalion, hence, on success over the longerterm, needs to be critically considered. Guarding the flank of the battalion implies a longer term purpose of staying ready to move when the battalion moves. Becoming bogged down in a fight at Sanna's Post may make this difficult and cause the battalion's flank to be exposed in the future. After training, references by officers to this longer-range or higherlevel purpose increased significantly in their accounts of their reasoning $(F(1,50)=7.024 ; p=$ $0.011)$. In the pretest only $3 \%$ of the participants mentioned the importance of maintaining contact with the battalion as it moved, whereas $26.3 \%$ did so after training.

Proaction. A proactive time orientation can be adopted at any level of planning. For example, in the Sanna's Post scenario, longer-term proactive considerations might justify the decision to attack Sanna's Post in terms of the larger battalion fight, e.g., to prevent the enemy using the tanks positioned there against the battalion, to reduce the enemy's logistical support for the fight against the battalion, or to force the enemy to orient away from the battalion. Relatively short-term proactive tactics might also be adopted in an attack, e.g., use of surprise, speed, and multiple directions of attack by the company to create confusion at Sanna's Post. Training significantly increased the proportion of officers who used proactive plans in their favored course of action $(F(1,50)=5.016 ; p=0.030)$. A breakdown in terms of short-term versus long-term proactive elements reveals that the largest effect of training was on longer-term proactive planning $(F(1,50)=9.584$; $p=0.003)$ - but the difference was only marginally significant.

Predictive-reactive. The predictive-reactive time orientation (i.e., anticipating specific possibilities and making contingency plans) might also be adopted at either a short-term or a long-term level of planning. Long range plans might include contingencies for taking over the battalion main effort in case it became necessary. Short-range plans might include contingencies for acting in case of specific enemy movements on the road through Sanna' Post, or for deploying different types of forces in a company attack on Sanna's Post. Training significantly increased the proportion of officers who incorporated branches or contingencies into their plans, from $27.3 \%$ to $57.9 \%(F(1,50)=5.058$; $p=0.029)$. The size of the effect was larger for short-term than for long-term contingencies, but there was no significant difference.

Tactics. We also looked at the effects of training on the specific tactics that participants adopted. Officer's plans were categorized as either including or not including three non-mutually exclusive elements. All three showed significant changes after training. There was an increase from $15.2 \%$ to $47.4 \%$ in the use of artillery against Sanna's Post $(F(1,50)=6.969 ; p=0.011)$; an increase from $24.2 \%$ to $57.9 \%$ in the (possibly contingent) use of a ground attack against Sanna's Post $(F(1,50)=$ $6.386 ; p=0.015)$; and an increase from $39.4 \%$ to $78.9 \%$, in the defense of two river fords from high ground against enemy reinforcement of the battalion 
$(F(1,50)=8.546 ; p=0.005)$. A correlational analysis (using Pathfinder) showed that the effects of training on all three tactical elements, as well as on the use of contingency plans, was mediated by the direct effect of training on proactive planning.

Prediction. Training had no effect on the use of the predictive time orientation, e.g., calculating the likelihood of success against the forces in Sanna's Post, or predicting the intent of the enemy there.

\section{SUMMARY AND CONCLUSION}

We did not assume that there was a single right answer in the Sanna's Post scenario. Rather, our interest was on the thought processes that lay behind participants' solutions. Actions based on prediction may get a jump on the enemy, but can fail if predictions are wrong. One way to deal with this risk is to take even more initiative, by attempting to proactively influence, rather than simply predict, the enemy's future actions (e.g., drive the enemy out of Sanna's Post before they can intervene in the battalion fight). But initiative creates another risk: diminished coordination with other friendly forces (e.g., loss of contact with the battalion). And this risk, in turn, can also be mitigated. One way is to heavily weight the purposes of higher level units (e.g., what is the long-range benefit or cost to the battalion of this action). The other way is to use contingency plans, to prepare ahead for situations in which plans may fail.

Training was designed to help officers balance the benefits and the risks of taking initiative in uncertain situations. The training was based on critical incident interviews in which we found that more experienced Army officers were more likely to plan proactively and to focus on higher-level purposes than less experienced officers. Training succeeded in making students more like experienced officers in these respects for a scenario in which the initial level of performance was not too high. It increased the frequency with which participants used a proactive time orientation to influence the enemy, thought about the impact of the initiative on higherlevel purposes, and made contingency plans in case things went wrong. Training also increased the use of three key tactical elements. In sum, the primary effects of training were (i) to get participants to take the initiative in shaping enemy decisions, and (ii) to ensure that such shaping served the higher-level purposes of the organization.

\section{ACKNOWLEDGMENTS}

This research was sponsored by Contract No. DASW01-97-C-0038 with the Army Research Institute, Fort Leavenworth, KA. We are grateful to Dr. Sharon Riedel, who was the scientific monitor of the project, and to LTC Billy Hadfield for his invaluable help. Others who contributed to this work are Terry Bresnick, Bryan B. Thompson, and Jonah I. Cohen.

\section{REFERENCES}

Brown, Lesley (Ed.) (1993). The new shorter Oxford English dictionary. Oxford: Clarendon Press. Cohen, M.S., Freeman, J.T., \& Wolf, S. (1996). Meta-recognition in time stressed decision making: Recognizing, critiquing, and correcting. $\mathrm{Hu}$ man Factors, 38(2), pp. 206-219.

Cohen, M.S., Thompson, B.B., Adelman, L., Bresnick, T.A., Shastri, L. \& Riedel, S. (2000). Training critical thinking for the battlefield. Arlington, VA: Cognitive Technologies, Inc.

Cohen, M.S., \& Thompson, B.B. (2001). Training teams to take initiative: Critical thinking in novel situations. In E. Salas (Ed.), Advances in Cognitive Engineering and Human Performance Research, Vol. 1. JAI.

March, J.G. (1996). Exploration and exploitation in organizational learning. In M.D. Cohen \& L.S. Sproull (Eds.), Organizational learning (pp. 101123). Thousand Oaks, CA: Sage Publications. 